\title{
Considerando aspectos culturais no (re)design da interação de Ambientes Virtuais de Aprendizagem
}

\author{
Jean Rosa, Ecivaldo Matos \\ Departamento de Ciência da Computação - Instituto de Matemática \\ Universidade Federal da Bahia (UFBA) \\ Av. Adhemar de Barros, s/n, Ondina \\ Salvador - BA - Brasil \\ \{jean.rosa, ecivaldo\}@ufba.br
}

\begin{abstract}
Resumo. Os Ambientes Virtuais de Aprendizagem (AVA) são softwares educacionais que favorecem a interação entre os estudantes e professores em cursos presencias e a distância. Além da qualidade da interação, outros elementos podem influenciar a efetividade do uso do AVA, como os aspectos culturais. Este artigo apresenta como está sendo delineada a pesquisa sobre (re)design participativo de um AVA voltado à educação escolar, considerando os aspectos pedagógicos e culturais, ao mesmo tempo que avalia em que medida a relação técnico-pedagógico-cultural se estabelece em um processo de design participativo de software educacional.
\end{abstract}

\section{Introdução}

Os Ambientes Virtuais de Aprendizagem (AVA) são softwares educacionais que favorecem a interação entre os estudantes e professores, seja no apoio a cursos presenciais ou cursos a distância. Segundo Santos e Schneider (2010), a participação dos sujeitos-usuários (ou seus representantes) desde o início do desenvolvimento de um AVA, pode ser decisivo quanto à qualidade da interação do ponto de vista da usabilidade.

A qualidade da interação desses ambientes há algum tempo tem sido preocupação de estudiosos do campo da Informática na Educação e da Interação Humano-Computador (IHC), dado que essa qualidade pode influenciar nos processos de ensino e de aprendizagem mediatizado por software educacional como afirma Matos (2013) e Rosa, Schwarzelmüller e Matos (2015). Todavia, além dos aspectos técnicos, outros elementos de natureza social, organizacional, pedagógica ou cultural podem influenciar a efetividade do uso de AVA (Gasparini, 2013).

De acordo com Gasparini (2013), sistemas apropriados para algumas culturas podem ser inapropriados para outras, pois um determinado contexto cultural faz com que os sujeitos-usuários utilizem signos próprios, desconsiderando aqueles que por ventura sejam desconhecidos. Isso faz com que esses sujeitos estabeleçam porções ou funcionalidades do software para uso, em detrimento de outros. Pereira et al. (2014) aponta que apesar de os pesquisadores de IHC reconhecerem a importância dos aspectos 
culturais na construção de softwares, ainda há poucos estudos que contemplam esses aspectos.

Nesse sentido, este artigo procura apresentar uma pesquisa em desenvolvimento, que busca, entre outras coisas, uma possibilidade dialógica e dialética de inclusão dos sujeitos-usuários no processo de (re)design da interação de um AVA, considerando os aspectos pedagógico-culturais, ao mesmo tempo que avalia em que medida a relação técnico-pedagógico-cultural se estabelece em um processo de design participativo de software educacional.

Este artigo está dividido em cinco seções. A próxima seção expõe a importância da cultura escolar nos processos pedagógicos subjacentes ao uso de qualquer tecnologia ou proposta didática, bem como apresentar diferentes conceitos de cultura e como ela tem sido tratada na Ciência da Computação (por meio dos estudos de IHC). Na Seção 2 discute-se a importância dos sujeitos-usuários no (re)design da interação de AVA. A metodologia de pesquisa empregada na pesquisa é apresentada na Seção 3; e, por fim, a Seção 4 apresenta as os resultados parciais e as próximas etapas.

\section{Cultura como aspecto considerável no design de softwares educacionais}

Com as mudanças de paradigmas sociais, o desenvolvimento tecnológico e a introdução de tecnologias digitais nas escolas, surgem a cada momento novas formas de ensinar e de aprender (Matos, 2013; Huang, 2014). Para Huang (2014), a aprendizagem mediatizada por artefatos computacionais favorece a construção de conhecimento; entretanto a sua introdução em ambiente escolar, nos traz diversos desafios, alguns de natureza tecnológica, outros pedagógicos ou, até mesmo, de gestão e infraestrutura.

Sendo a escola uma instituição multicultural (Hall, 2003), formada por sujeitos oriundos de diferentes micro e macro realidades sócio-antropológico-sociais, os softwares que serão concebidos para auxiliar os professores e estudantes devem considerar aspectos culturais próprios do ambiente escolar (Candau, 2013). Dado que esses aspectos têm forte impacto nos processos cognitivos e afetivos relacionados a aprendizagem e por isso, tanto a IHC quanto a Informática na Educação devem considerar a cultura em AVA.

Mas, para a primeira utilização de um software, de acordo com Matos (p. 1, 2008), "os usuários não chegam com as mentes vazias frente às telas dos computadores" uma vez que trazem consigo um sistema de significação construído socioculturalmente. O sistema de significação é estudado pela Semiótica e diz respeito ao conjunto de signos pessoais formulados dentro de um contexto social e/ou cultural.

Estudiosos de IHC tem considerado a cultura de acordo com a ótica de Khaslavsky (1998):

[...] um sistema de significados compartilhados que formam um quadro para a resolução de problemas e comportamento na vida cotidiana. Os indivíduos se comunicam uns com os outros através da atribuição de significado às mensagens com base em suas crenças anteriores, atitudes e valores. (p. 1, tradução nossa) 
No campo da Antropologia, historicamente estudiosa da cultura, há diferentes acepções para a palavra "cultura". Destacamos o a conceito apresentado por Laraia (1986), muito próximo à definição estabelecida por Khaslavsky, em que a cultura é "um sistema de símbolos e significados. Compreende as categorias ou unidades e regras sobre relações e modos de comportamento [...]" (p. 63). Seria, portanto, a Semiótica a lógica da cultura.

Para a correta interpretação dos signos por partes dos interlocutores (designers e usuários) durante a interação é importante que os signos expressos na interface do software estejam contidos do sistema de significação dos interlocutores (designers e sujeitos-usuários), culturalmente construído.

É de responsabilidade dos designers de interação que os sistemas concebidos não provoquem efeitos indesejados nos usuários em contexto de uso (Pereira et al., 2014). Então, como viabilizar que os designers conheçam o sistema de significação dos sujeitos-usuários?

A partir dessa questão surgiu a seguinte hipótese: se os usuários forem coautores do design da interação do AVA, seria possível ao designer compreender os signos que participam do sistema significativo dos seus sujeitos-usuários, adequando as interfaces do AVA às necessidades desses sujeitos. Tendo em vista a validação dessa hipótese, a pesquisa em desenvolvimento busca entender como inserir efetivamente os sujeitosusuários em um processo semioparticipativo de design de interação de um AVA considerando aspectos técnicos, pedagógicos e culturais.

“A expressão 'semioparticipativo' representa um termo genérico para práticas participativas que carregam mensagens, ou seja, o estudo da comunicação entre os agentes tornada efetiva por meio de sua participação no design" (Baranauskas et al., 2013, p. 49). Essas práticas podem auxiliar na concepção do design da interação considerando os aspectos culturais dos usuários devido os mesmos trazerem consigo as suas características culturais, sociais, econômicas e políticas para ser introduzido no design da interação do AVA.

Mediante a aplicação de práticas participativas na construção do design, as partes interessadas devem participar colaborativamente e/ou cooperativamente para construir a interface do AVA baseado no sistema significativo do designer e das partes interessadas. Com os ícones, índices e símbolos da interface construídos baseado no sistema significativo dos usuários espera-se que a interação entre os usuários e o AVA não seja tão complexa e distanciada do seu contexto cultural.

\section{Metodologia}

Para buscar responder à questão norteadora dessa pesquisa é importante o entendimento de que práticas participativas no (re)design da interação de AVA possibilitam aos usuários serem codesigners da interação. Para isso foi desenvolvida uma revisão sistemática sobre essas práticas. Nessa revisão foram analisados teses, dissertações e artigos das áreas de Design, Educação, Educação Matemática e Ciência da Computação. Todavia, poucos artigos apresentaram como temática central os aspectos culturais 
envolvidos na interação técnico-pedagógica de sujeitos-usuários com sistemas computacionais interativos. Com a análise dessa revisão foi possível definir uma abordagem participativo para redesign da interação do ambiente socioeducacional TecCiencia.

Definida a abordagem, iniciou-se o procedimento de pesquisa-ação junto a professores de diferentes disciplinas de um colégio público em Salvador/BA. O primeiro passo foi a apresentação do ambiente socioeducacional, voltado à educação escolar, baseado em tecnologias livres, o TecCiencia, suas funcionalidades e possibilidades de interação social e pedagógica (Rosa, Schwarzelmüller e Matos 2015). Nesse momento foram discutidos os desafios de inclusão efetiva dessa tecnologia no cotidiano escolar daquela unidade de ensino. Junto com os professores que aceitaram participar da pesquisa iniciamos a definição de um protocolo de trabalho, no qual a partir do uso do ambiente, eles e uma amostra de estudantes, mediados pelos pesquisadores, definirão, a partir de uma proposta de pesquisa-ação, os problemas de interação e como poderão ser solucionados.

Ao longo da pesquisa-ação serão utilizadas as seguintes técnicas: acompanhamento e registro do uso do TecCiencia; Grupos focais; análise de conteúdo (Bardin, 2009) a partir de três abordagens dialeticamente estabelecidas - técnica, pedagógica e cultural.

Desse modo, o grupo (pesquisadores e sujeitos) farão a análise da situação atual do sistema, seus problemas de interação técnica e pedagógica e, os problemas culturais. Para avaliação da interação será utilizado um método da Engenharia Semiótica, por esta considerar fundamentalmente, a natureza signica e cultural da interação. Então, por meio do Método de Avaliação da Comunicabilidade (MAC) tentar-se-á encontrar possíveis rupturas da comunicação no processo de interação com o AVA.

Após encontrar os problemas de comunicabilidade utilizaremos procederemos com o redesign participativo respeitando a cultura dos alunos e professores e todo o seu contexto escolar.

\section{Considerações Finais}

Com a revisão de estudos anteriores, percebemos a importância de articulação epistêmica entre a Informática na Educação, a Interação Humano-Computador e os estudos sobre Cultura e Cotidiano Escolar, no âmbito das Ciências da Educação. Dado que o objeto de investigação é complexo e envolve intrinsecamente elementos interdisciplinares que estão para além da técnica.

Neste trabalho consideramos fundamentalmente o elemento cultura. Após o levantamento de estudos e início da pesquisa-ação, foi notório como aspectos culturais influenciam antes de tudo a percepção dos sujeitos com relação ao sistema e, especialmente, os desdobramentos do seu uso em ambiente escolar, embebido de elementos pedagógicos, mas também políticos e culturais. 
As próximas etapas desta pesquisa são: estabelecimento dos grupos focais; levantamento das variáveis técnicas, pedagógicas e culturas; análise de conteúdo híbrido-dialético, a partir de uma teoria da IHC, uma teoria de aprendizagem e uma teoria de cultura. De modo a estabelecer-se o redesign semio-dialético-participativo do ambiente socioeducacional TecCiencia.

\section{Referências}

Baranauskas, M. C. C.; Martins, M. C.; Valente, J. A. (org) (2013). Codesign de Redes Digitais: tecnologia e educação a serviço da inclusão social. Porto Alegre: Penso.

Bardin, L (2009). Análise de conteúdo. Lisboa (Portugal): Edições 70.

Candau, V. M. (2013). Multiculturalismo e educação: desafios para a prática pedagógica. In: Candau, V. M.; Moreira, A. F. [Eds.]. Multiculturalismo: diferenças culturais e práticas pedagógicas. 10. ed. Petrópolis: Vozes.

Gasparini, I. (2013). Aspectos Culturais no Modelo do Usuário em Sistemas Adaptativos Educacionais: Fundamentos, Proposta e Experimentação. Tese (Doutorado em Computação). Instituto de Informática - Universidade Federal do Rio Grande do Sul - UFRGS.

Hall, S. (2003). Da diáspora: Identidades e Mediações Culturais. Brasília: Editora UFMG.

Huang, T. K. (2014). Investigating User Acceptance of a Screenshot-Based Interaction System in the Context of Advanced Computer Software Learning. In Anais 47th Hawaii International Conference on System Sciences.

Khaslavsky, J. (1998). Integrating culture into interface design. CHI 98 conference summary on Human factors in computing systems, p. 365-366.

Laraia, R. B. (1986). Cultura: um conceito antropológico. Rio de Janeiro: Zahar.

Matos, E. S. (2008). Raciocínio Semiótico Abdutivo e Conhecimentos Prévios na Aquisição de Conhecimentos Inerentes à Interação Humano-Computador. In: Anais VIII Brazilian Symposium on Human Factors in Computing Systems.

(2013). Dialética da Interação Humano-Computador: tratamento didático do diálogo midiatizado. Tese (Doutorado em Educação). Faculdade de Educação Universidade de São Paulo - USP.

Pereira, R., Gasparini, I.; Salgado, L. (2014). Cultura Importa e faz Diferença: uma Discussão sobre os Grandes Desafios de Pesquisa em IHC no Brasil. In: Brazilian Symposium on Human Factors in Computing Systems.

Rosa, J.; Schwarzelmüller, A. F.; Matos, E. (2015). Avaliação heurística da rede social educacional TecCiencia. In: Anais XV Escola Regional de Computação Bahia Alagoas - Sergipe.

Santos, G. A. dos; Schneider, H. N. (2010). Avaliação de Usabilidade de Ambientes Virtuais de Aprendizagem. In: Anais $3^{\circ}$ Simpósio Hipertexto e Tecnologias na Educação. 